\title{
Money in a Developing Economy: A Reappraisal
}

\author{
by \\ WAYNE W. SNYDER
}

\author{
CRED Reprints \\ (New Series) \\ No. 11
}
Center for Research on Economic Development
University of Michigan
Ann Arbor, Michigan 48104





\section{Reprinted from}

The Review of Economics and Statistics

Published by Harvard University

Copyright, 1970, by the President and Fellows of Harvard College

Vol. LII, No. 1, February 1970 


\title{
MONEY IN A DEVELOPING ECONOMY: A REAPPRAISAL
}

\author{
Wayne W. Snyder*
}

GEVERAL years ago I proposed a theory to Sexplain how the money supply in a developing country is determined which allows for factors other than the traditionally assumed control by a central bank [6]. Its validity was tested with an econometric quarterly model for Pakistan, 1953-1961. The passage of time makes it possible to reappraise the model which is the purpose of this paper.

With the benefit of hindsight and reflections about economic model building, the reappraisal suggests that what I proposed as a general description of money in a developing economy, in fact, more closely resembled a stationary one. Although some differences of opinion exist, economists agree that Pakistan's development during the 1950's was far less dynamic, albeit certainly not nonexistent, than what has since occurred. $^{1}$ My purpose, however, is not to propose a revised theory of how the money supply is really determined in a developing economy, but rather to appraise quantitatively the extent to which the model's predictive capacity after 1961 differs from its performance during the original period. Though this is a more modest objective than attempting to reconstruct a theory which would incorporate the important developments of the 1960's, appraising the predictive capacity of econometric models during periods beyond that which was used for the original fitting, is a worthwhile endeavor which economists should more frequently practice.

The postwar era has seen a tremendous growth in econometric studies. Generally, they have two features in common. First, although they really belong to the realm of economic history because the objective is to obtain the best fit to explain a set of data for some past period, the hope is usually present that the estimated relationships should be useful to understand

* This paper benefited from valuable conversations with Lester Taylor, who along with Richard Porter read and commented on an earlier version; Ziauddin Ahmad proved himself a true friend by rapidly supplying the necessary data; and helpful editorial suggestions were made by Janet Eckstein.

${ }^{1}$ Papanek [5, p. 7] and Griffin [2, p. 613] disagree somewhat about how much particular sectors grew in Pakistan during various periods, but both generally acknowledge that development has been substantially more rapid since 1960 than it was previously. (i.e., predict) future changes, given a new set of new exogenous conditions. Second, except for narrowly conceived forecasting models which are often revised annually, we rarely have an opportunity to judge whether history repeats itself in the sense that the model's predictive capacity remains high for a new period beyond the time for which the original parameters were estimated. ${ }^{2}$ As has been suggested elsewhere, the infrequent publication of the predictive performance of econometric models is due to the fact that "few investigators are willing to choose a specification on the basis of less than a complete set of the available data" $\left[3\right.$, p. 11]. ${ }^{3}$ Here, I hope to make amends for not having practiced in my original article what is here preached about the testing for predictive performance.

My earlier article showed that the predictive performance of the model's structural equations was generally good and, furthermore, the model's capacity to explain the money supply was demonstrated to be superior to a simple "money multiplier" model where certain controllable assets of the central bank were used to predict the money supply. One simulation experiment which used the original initial conditions and the values of the exogenous variables produced a new set of predicted values which suggested that the model was quite stable, at least over the 34 quarters between July 1953 and December 1961, for which the parameters were estimated.

In this paper I test, during 24 additional quarterly observations for the years 1962

${ }^{2}$ One important and notable exception is the exhaustive
study made by Jorgenson and Nadiri [4] of the predictive
performance of four alternative econometric models of quar-
terly investment behavior where functions fitted to data of
an earlier period are used to predict data for a later period.
'Another deficiency of econometric studies is that the
amount of fishing done in order to obtain the "best fit" is
almost never reported, although it directly affects the proba-
bility of achieving a high $\overline{\boldsymbol{R}}^{2}$. Publishing a fishing schedule
and testing for predictive capacity should both become ex-
pected norms of econometric studies. This may seem
academic, utopian, or unnecessarily restrictive depending
upon one's view, but during the past ten years we have
already seen several norms develop, such as the transition
from publishing the coefficient of correlation to the coeffi-
cient of determination, the reporting of the coefficient
adjusted for degrees of freedom, and the inclusion of the
Durbin-Watson test for serial correlation of the error terms.


through 1967, the predictive capacity of the originally estimated equations in three ways. First, the structural equations are examined for change in the underlying structure by using methods described by Johnston [3, pp. 136138]. Briefly, the relations can be tested for changes in the coefficients between the original period of fit (1953-1961) and the latter period (1962-1967) by an $F$-ratio of the appropriate combination of the sum of squared prediction errors. Although some differences in degrees of freedom exist among the various equations tested, the null hypothesis that no significant change occurred can be rejected at the 0.01 level if $F>2.0$ for any function. ${ }^{4}$ This is a much stronger test than comparing the goodness of fit alone. Second, an even stronger test is made by creating a new simulation experiment which uses the data for all variables during the last quarter of the original period (OctoberDecember 1961) as the initial conditions for a new simulation of 24 quarters, where predicted values use the previous quarter's predictions rather than given values. This type of simulation excludes correcting for prediction errors because they tend to accumulate over the period if the model is unstable or if the errors are autocorrelated. Last, simulated values of the money supply are compared with predictions of the simple "money multiplier" model, using the originally estimated coefficients.

\section{The Original Econometric Model}

The following simplified set of asset and liability statements ( $T$-accounts) was used to explain how the money supply was determined.

\begin{tabular}{c|cc|c}
\multicolumn{2}{c}{ State Bank of Pakistan } & \multicolumn{2}{c}{ Commercial Bank } \\
X & N & VC & D \\
B & VC & RR & B \\
& RR & ER & \\
& ER & Y &
\end{tabular}

\footnotetext{
4 This test evaluates the combined change due to differences in the parameters associated with the explanatory variables. Another variation of this test permits investigating for a change of any subset, and hence for individual coefficients [1, pp. 559-602]. This detailed examination is not pursued, however, because overall differences are generally so substantial that no single coefficient is likely to have escaped significant changes.
}

The model included behavioral functions to explain demand deposits $(D)$, vault cash $(V C)$, commercial bank lending to the private sector $(L)$, and commercial bank borrowing from the SBP $(B)$; a statutory regulation determines the amount of required reserves $(R R)$. Excess reserves $(E R)$ and SBP bank notes $(N)$ held outside the banking sector become variables determined by these five functions and by the necessity that two accounting identities must be satisfied:

$$
\begin{aligned}
& X+B=N+V C+R R+E R \\
& V C+R R+E R+Y+L=D+B
\end{aligned}
$$

These relationships incorporate seven endogenous variables and two exogenous ones, $X$ and $Y$ (other net assets of the SBP and the commercial banking sector, respectively). Thus, the money supply $(N+D)$ is determined simultaneously and is not explicitly specified, although a complicated "reduced form" equation for its determination is implicit in the model. All figures are in millions of rupees unless otherwise indicated.

\section{Demand Deposits}

The equation explaining demand deposits in the original model was chosen to account for the fact that currency is a more important component of the money supply than demand deposits in most developing countries. Demand deposits, it was argued, are created as currency flows into commercial banks, rather than being diminished to the extent that currency leaks out of the banking sector as in the financially mature economies. A one-period lag was used to express this hypothesis, where $N_{o}$ is the previous peak value of $N$, and seasonal variation in the first quarter was found to be significant. ${ }^{5}$

$$
\frac{D_{t}}{N_{t-1}}=a+\beta \frac{N_{t-1}}{N_{o}}+\gamma \frac{D_{t-1}}{N_{t-2}}+\delta Q_{1}+\mu .
$$

The test for change in the coefficients between the earlier and the latter periods produces $F=5.2$ which indicates the relationship

\footnotetext{
${ }^{5}$ Lester Taylor has pointed out that seasonal dummy variables should always be tested as a group and that individual dummy variables should not be excluded when they are insignificantly different from zero, because they can still be significantly different from each other which is the relevant consideration. For consistency with the model, however, the original specification is retained.
} 
was highly unstable. This can be seen directly by comparing the three regressions for relationship (3) which are given in table 1 . The variable $N_{t-1} / N_{o}$ diminishes in importance from the first to the second period, and is even less important for the 1953-1967 period as a whole. Concurrently, the coefficient for the autoregressive factor, $D_{t-1} / N_{t-2}$, gains importance. The reasons for the changing coefficients can be easily seen in figure 1 . The ratio $D_{t} / N_{t-1}$ from 1953 through 1961 fluctuated some and the medium-term trend was first downward and afterwards upward, but the value in December 1961 was about the same as eight years earlier. In contrast, between the end of 1961 and 1967, the ratio increased substantially. The only way for equation (3) to account for this change was for the autoregressive factor to pick up the secular trend which occurred after 1953. The Durbin-Watson coefficient increased significantly, as one would expect. as suggested by Johnston [3, pp. 207-211], but no such specification seemed necessary for the original period.

Equation (3) is a good approximation of how the split of the money supply between demand deposits and currency occurs in a traditional society where currency is the principal monetary asset, but it does not function well to explain the increasing importance of demand deposits when the banking sector really begins to develop. For example, in the first period it was impossible to obtain a significant coefficient for the variable, bank branches. Little wonder because the average increase was only 50 per year as compared with 350 per year during the second period.

The simulation experiment shows rather forcefully how inadequate equation (3) is in explaining the growing importance of demand deposits relative to currency, as the simulated ratio increasingly diverges from the actual ratio

Table 1. - Regression Results for Demand Deposits a

\begin{tabular}{|c|c|c|c|c|c|c|c|c|}
\hline Period & $\begin{array}{c}\text { Quarterly } \\
\text { Observations }\end{array}$ & $a$ & $\beta$ & $\gamma$ & $\delta$ & $\bar{R}^{2}$ & $S_{e}$ & D.W. \\
\hline $1953-1961$ & 34 & 0.41 & $\begin{array}{c}-0.29 \\
(3.71)\end{array}$ & $\begin{array}{c}0.79 \\
(7.90)\end{array}$ & $\begin{array}{c}-0.02 \\
(2.09)\end{array}$ & 0.76 & 0.02 & 2.15 \\
\hline $1962-1967$ & 24 & 0.32 & $\begin{array}{c}-0.20 \\
(1.11)\end{array}$ & $\begin{array}{c}0.88 \\
(7.10)\end{array}$ & $\begin{array}{c}-0.10 \\
(4.48)\end{array}$ & 0.76 & 0.04 & 2.74 \\
\hline 1953-1967 & 58 & 0.22 & $\begin{array}{c}-0.20 \\
(2.04)\end{array}$ & $\begin{array}{c}1.01 \\
(24.56)\end{array}$ & $\begin{array}{c}-0.06 \\
(5.08)\end{array}$ & 0.92 & 0.03 & 2.94 \\
\hline
\end{tabular}

a $\bar{R}^{2}=$ coefficient of determination adjusted for degrees of freedom; $S e=$ standard error of estimate; D.W. = Durbin-Watson statistic; $t$-statistic in parentheses.

This explains why the $\bar{R}^{2}$ for the entire period is substantially larger than for each subperiod. Because the mean value of $D_{t} / N_{t-1}$ is so much larger in the latter period than in the former, although the percentage of explained variance in each subperiod is identical, the percentage of explained variance for the entire period is greatly increased.

It should also be noted that the standard error in the latter period is twice as large as in the former. Thus, the implicit assumption of homoscedasticity is clearly violated. In cases such as this where secular trend occurs, one should expect - at least with the benefit of hindsight - to observe hetroscedasticity which can sometimes be handled by allowing for the standard error of the disturbance term to increase in proportion to the predictive variables between 1962 and 1967 (see figure 1). Whereas the $\bar{R}^{2}=.59$ between the simulated and actual values of $D_{t} / N_{t-1}$ during the first period, it fell to merely 0.15 in the latter period, using the first period's coefficients for both periods.

\section{Vault Cash}

Although one might expect vault cash to be a function of both demand and time deposits, only the coefficient for the former was significant in the original model. In addition, the number of bank branches $(\mathrm{Br})$ was found to be significant as were seasonal variations in the second and fourth quarters, especially the latter when window dressing for annual reports is important. $^{6}$

\footnotetext{
${ }^{8}$ See footnote 5 .
} 
Figure 1. - Actual, Predicted and Simulated Values for Commercial Bank

Borrowing from the SBP, Vault Cash, Excess Reserves and $D_{t} / N_{t-1}$

Millions of Rupees (except for $\frac{D_{t}}{N_{t-1}}$ )

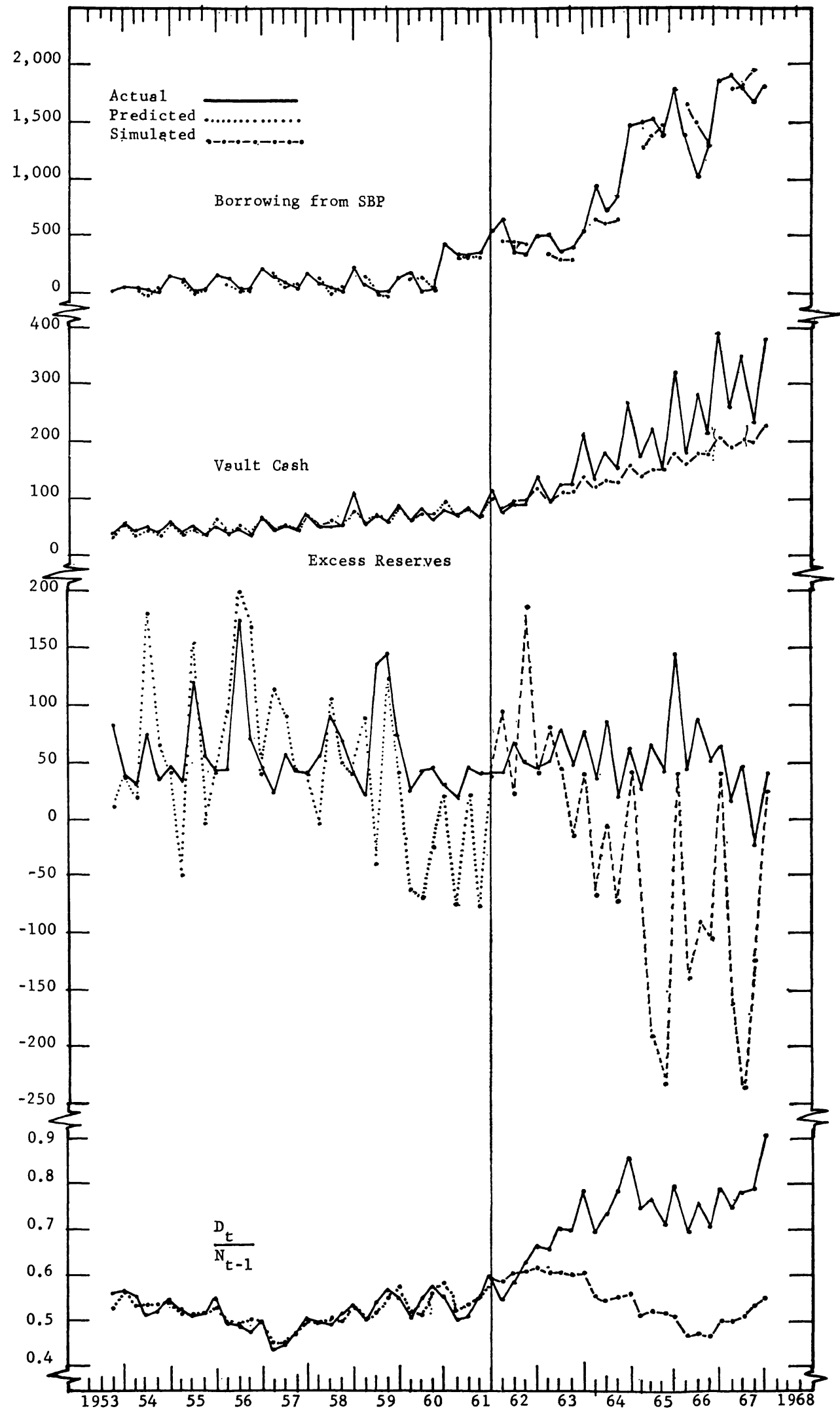




$$
V C_{t}=a+\beta D_{t}+\gamma B r_{t}+\delta Q_{2}+\epsilon Q_{4}+\mu .
$$

The test for combined change in the coefficients gives $F=12.9$, hence they are even more highly unstable than the coefficients of equation (3). Several factors are responsible. Seasonal variation was about three times as important in the latter than in the former period (see figure 1). Partially, this could have been taken care of by allowing for an appropriate form of time trend in the seasonal dummy variables. More important, while the attempt to include time deposits did not result in a significant coefficient for the original period, this was because the absolute size of time deposits was so small relative to demand deposits. The rate of growth of time deposits, however, was more than twice as rapid as demand deposits so that by the end of 1967 they were 20 per cent larger than demand deposits. Hence, including them in a relationship to explain vault cash becomes increasingly necessary, and as originally reported, ceteris paribus, banks appear to hold about 3 per cent as vault cash reserves for demand deposits and 1 per cent for time deposits [6, p. 415]. Again it should be noted that the standard error is substantially larger in the latter period than in the former, thus violating the assumption of homoscedasticity.

The simulation test which uses coefficients fitted for the 1953-1961 data to predict vault

\section{Commercial Bank Lending to the Private Sector}

The original hypothesis was that commercial banks in developing countries traditionally lend to finance foreign trade and the major domestic cash crops, but exports $(E)$ and imports $(M)$ alone were found to be adequate predictors. In Pakistan, banks are generally free to borrow from the SBP to meet their recognized demand, but various degrees of restraint are imposed during the busy season, the fourth quarter. This was incorporated in the equation to explain the change in bank lending, $\triangle L_{t}$, by fitting it to the first three quarters only of each year, seasonal variation was significant for all three quarters.

$$
\begin{gathered}
\Delta L_{t}=a+\beta E_{t}+\gamma E_{t+1}+\delta\left(M_{t}+M_{t+1}\right) \\
+\epsilon Q_{1}+\eta Q_{3}+\mu \\
(t=1,2,3,5,6,7,9, \ldots) .
\end{gathered}
$$

An explanation of bank lending is crucial because it is a major determinant of the money supply in the identity $M=N+D=X+Y$ $+L$. The original equation's $\bar{R}^{2}=0.76$ was somewhat lower than for any other structural equation in the model. The test for equation (5)'s homogeneity of coefficients gave $F=7.3$, again indicating substantial change. In fact, exports and imports completely fail to contribute to the explanation of bank lending after 1961. The reason is not difficult to pinpoint.

Table 2. - Regression Results for Vault Cash

\begin{tabular}{cccccccccc}
\hline \hline Period & $\begin{array}{c}\text { Quarterly } \\
\text { Observations }\end{array}$ & $a$ & $\beta$ & $\gamma$ & $\delta$ & $\epsilon$ & $\bar{R}^{2}$ & $S e$ & D.W. \\
\hline $1953-1961$ & 34 & -8.52 & 0.03 & 0.05 & 9.94 & 25.46 & 0.83 & 7.43 & 1.97 \\
& & & $(3.14)$ & $(1.90)$ & $(2.67)$ & $(7.98)$ & & \\
$1962-1967$ & 24 & -166.98 & 0.11 & -0.02 & 24.61 & 81.94 & 0.96 & 19.65 & 2.45 \\
& & & $(3.49)$ & $(0.47)$ & $(1.95)$ & $(6.79)$ & & \multirow{2}{*}{2.06} & 2.65 \\
$1953-1967$ & 58 & -64.19 & 0.06 & 0.04 & 20.18 & 54.05 & 0.94 & 22.06 \\
& & & $(3.41)$ & $(1.50)$ & $(2.70)$ & $(7.60)$ & & & \\
\hline
\end{tabular}

cash during 1962-1967, where the explanatory values of demand deposits are also simulated values and not actual values, gives the fairly good result of $\bar{R}^{2}=.87$ which is comparable with the similar simulation experiment done for the earlier period. But the fairly high $\bar{R}^{2}$ mostly reflects merely the collinearity between vault cash and demand deposits as much of the secular trend is missed as well as the previously noted increasing importance of seasonal variation (see figure 1).
Bank lending increased at a rate which was 50 per cent greater on the average during the second period (see figure 2), whereas the volume of privately financed foreign trade increased at an identical rate in both periods. Hence, exports and imports could not possibly account for the new secular trend in bank lending after 1961 which caused the dummy seasonal variables to try and absorb as much as they could (see table 3 ). Commercial banking practices changed rapidly too as banks began 
Table 3. - Regression Results for Bank Lending

\begin{tabular}{ccccccccccc}
\hline \hline Period & $\begin{array}{c}\text { Quarterly } \\
\text { Observations }\end{array}$ & $\alpha$ & $\beta$ & $\gamma$ & $\delta$ & $\epsilon$ & $\eta$ & $\bar{R}^{2}$ & $S e$ & D.W. \\
\hline $1953-1961$ & 25 & -154.85 & -0.59 & 0.13 & 0.37 & 197.97 & 88.23 & 0.73 & 47.36 & 2.12 \\
& & & $(2.96)$ & $(1.44)$ & $(3.36)$ & $(6.49)$ & $(2.25)$ & & \\
$1962-1967$ & \multirow{2}{*}{18} & 354.00 & -0.72 & 0.05 & 0.11 & 190.89 & -28.68 & $-0.27^{\mathrm{a}}$ & 250.76 & 1.33 \\
& & & $(0.66)$ & $(0.05)$ & $(0.32)$ & $(1.04)$ & $(0.14)$ & & & \\
$1953-1967$ & \multirow{2}{*}{43} & -141.08 & -0.32 & 0.43 & 0.11 & 156.27 & 31.18 & 0.15 & 159.26 & 1.25 \\
& & & $(0.79)$ & $(1.09)$ & $(0.79)$ & $(2.26)$ & $(0.35)$ & & & \\
\hline
\end{tabular}

a In practical terms the explained variance of $\Delta L$ is zero; the negative $\bar{R}^{2}$ is caused by the adjustment for degrees of freedom.

to expand their concept of "bankable loans" to include greater amounts and new types of domestic manufacturing for which their combined outstanding loans increased from about onefourth of total loans at the end of $1961[7, \mathrm{p}$. 32] to nearly one-half by December 1967 [8, p. 21].

The simulation experiment for lending is somewhat different than for the previous equations because lending is determined solely by exogenous variables (exports, imports, and seasonal dummies) during the first three quarters of each year, and limited by quantitative restrictions imposed by the SBP in the fourth quarter. Figure 2 shows how the simulated values for loans $\left(L_{t}=L_{t-1}+\triangle L_{t}\right.$, where $\triangle L_{t}$ is a simulated prediction) diverged from the actual levels after 1961. The simulation $\bar{R}^{2}=$ .98 in the latter period is identical with the comparable experiment for the earlier period. The reason for no discernible difference between the two periods is that although commercial bank lending to the private sector increased more rapidly than predictions based on foreign trade alone would account for, nevertheless the predictive variables explain a major portion of the secular trend although they fail to predict any of the quarterly change in commercial bank lending (see figure 2).

Borrowing by the Commercial Banks from the SBP

Bank borrowing from the SBP is at the general discretion of commercial banks during the first three quarters and quantitatively controlled by the SBP during the busy season, the fourth quarter. Its determination was argued to depend upon the level of borrowing in the previous quarter and the present level of free reserves $\left(F R_{t}=E R_{t}-B_{t}\right)$. In this form pres- ent borrowing would appear on both sides of the equation and it was necessary to transpose all borrowing to the left-hand side and use the two-stage least square method developed by Theil [9, pp. 225-240], because excess reserves is a simultaneously determined endogenous variable, before transforming the equation back into the form of the original hypothesis where seasonal variation in the first quarter is also accounted for.

$$
\begin{gathered}
B_{t}=a+\beta B_{t-1}+\gamma F R_{t}+\epsilon Q_{1}+\mu \\
(t=1,2,3,5,6,7,9, \ldots) .
\end{gathered}
$$

The hypothesis of no change in the coefficients of equation (6) was the only one among the model's four structural equations which could not be rejected at the 0.01 level $(F=$ 0.96). Thus, bank borrowing remained a fairly stable function throughout the entire period. In the simulation experiment for the second period, $\bar{R}^{2}=.88$ which was even somewhat higher than the $\bar{R}^{2}=.70$ obtained for the first period, mainly because the absolute variation in bank borrowing was so much greater in the latter period than in the former (see figure 1).

\section{Excess Reserves}

Excess reserves are residually determined during the first three quarters of each year and assumed to be reduced to an average minimum of 40 million rupees during the fourth quarter when the SBP quantitatively controls its lending to the commercial banks and thus creates a premium on excess reserves which is reflected in a seasonal rise in the call money rate. There is no structural equation for excess reserves, hence no possibility of using the $F$-test. But their simulated values is an over-all indication of the model's stability, and the $\bar{R}^{2}$ was only 
Figure 2. - Actual, Predicted and Simulated Values for Money and Credit

Miliions of Rupees

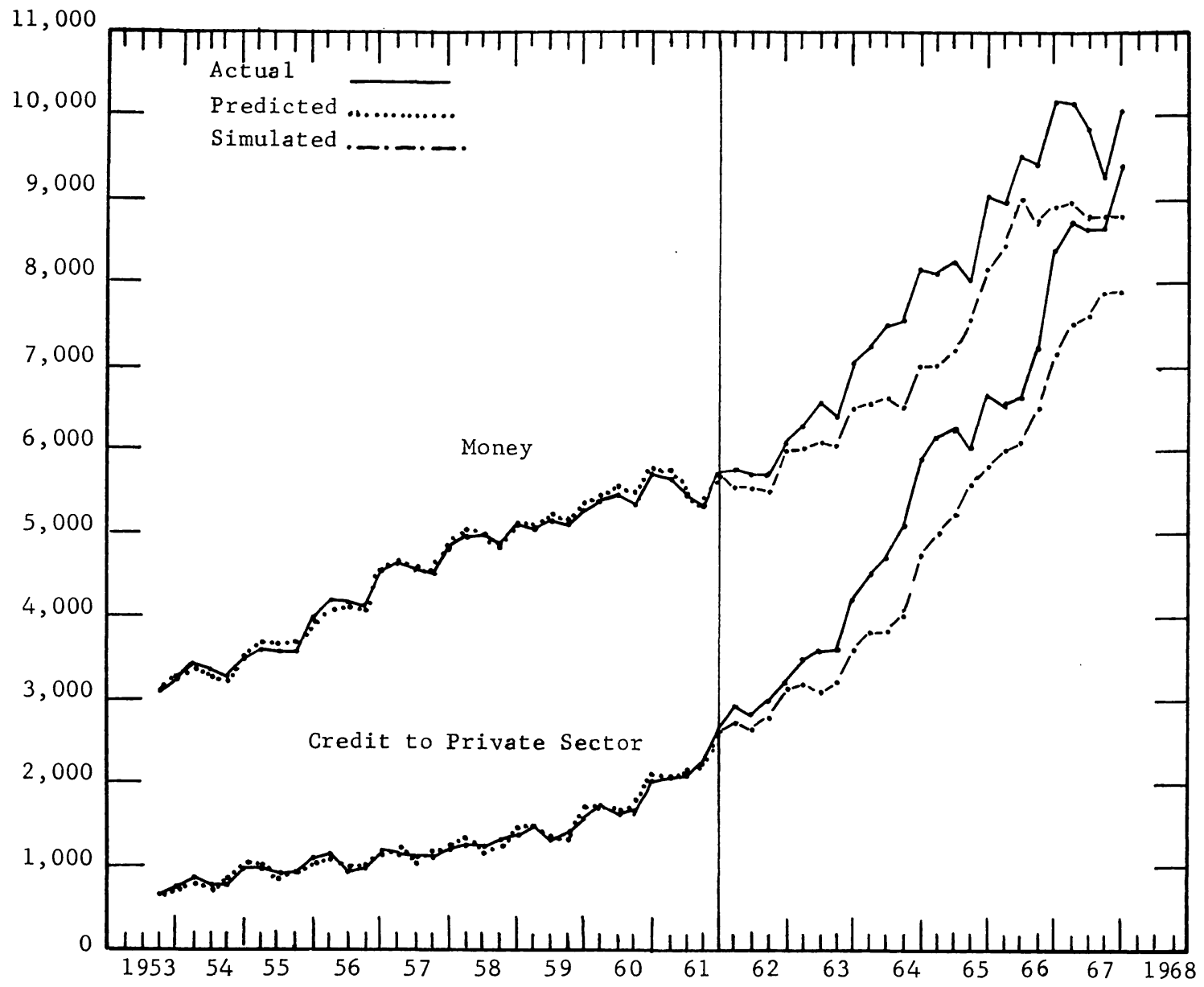

0.15 in the second period as compared with 0.49 in the first period.

\section{Predicting the Money Supply}

The above relationships (and the statutory reserve requirement) along with the two accounting identities are sufficient to determine the amount of currency, and as demand deposits are estimated from equation (3), the money supply, $M=D+N$, is also determined. It is not meaningful to use the $F$-ratio to test for coefficient stability, the implicit "reduced form" equation for the money supply, but a simulation experiment is a good indicator of the model's stability unless there are offsetting

TABLE 4. - Regression Results FOR BORROWING From the SBP

\begin{tabular}{|c|c|c|c|c|c|c|c|c|}
\hline Period & $\begin{array}{c}\text { Quarterly } \\
\text { Observations }\end{array}$ & $a$ & $\beta$ & $\gamma$ & $\epsilon$ & $\bar{R}^{2}$ & $S_{e}$ & D.W \\
\hline $1953-1961$ & 25 & 48.65 & $\begin{array}{c}0.26 \\
(7.81)\end{array}$ & $\begin{array}{c}-0.64 \\
(4.32)\end{array}$ & $\begin{array}{r}-26.47 \\
(2.79)\end{array}$ & .84 & 41.82 & 2.40 \\
\hline $1962-1967$ & 18 & 64.05 & $\begin{array}{c}0.19 \\
(9.68)\end{array}$ & $\begin{array}{c}-0.76 \\
(1.68)\end{array}$ & $\begin{array}{l}15.53 \\
(0.68)\end{array}$ & .88 & 185.97 & 1.78 \\
\hline $1953-1967$ & 43 & 51.23 & $\begin{array}{c}0.21 \\
(24.63)\end{array}$ & $\begin{array}{c}-0.76 \\
(3.27)\end{array}$ & $\begin{array}{r}-14.53 \\
(1.19)\end{array}$ & .96 & 123.02 & 1.87 \\
\hline
\end{tabular}


TABle 5. $-\bar{R}^{2}$ FOR THE MOdel Using ORIGINAL and New CoEFficients ${ }^{\text {a }}$

\begin{tabular}{cccccc}
\hline \hline \multicolumn{6}{c}{ Using Original Coefficients } \\
1953-1961 & 1962-1967 & \multicolumn{2}{c}{ Using New Coefficients } \\
$1962-1967$ & $\begin{array}{c}1953-1967 \\
\text { 1950 }\end{array}$ \\
Variable & Prediction & Simulation & Simulation & Prediction & Prediction \\
\hline$M_{t}{ }^{s}$ & .99 & .99 & .96 & .98 & .95 \\
$L_{t}$ & .99 & .98 & .98 & .99 & .99 \\
$D_{t} / N_{t-1}$ & .76 & .59 & .15 & .72 & .92 \\
$V C_{t}$ & .83 & .85 & .87 & .96 & .94 \\
$\Delta L_{t}$ & .73 & .88 & .18 & .70 & .72 \\
$B_{t}$ & .84 & .70 & .88 & .88 & .96 \\
$E R_{t}$ & .20 & .49 & .14 & .00 & .01 \\
$\Delta M_{t}{ }^{s}$ & .92 & .92 & .31 & .73 & .72 \\
\hline
\end{tabular}

a All $\bar{R}^{2}$ are adjusted for degrees of freedom, but only those for the four structural equations explaining $D_{t} / N_{t-1}, V C_{t}, \Delta L_{t}$ and $B_{t}$ can be interpreted in the usual sense.

changes in the coefficients which give spurious value to the simulation. The simulated prediction of the level of the money supply is nearly as good in the second period as in the first $\left(\bar{R}^{2}=.96\right.$ and .99 , respectively), but the model's ability to predict changes in the money supply is substantially lower in the later than in the earlier period, $\bar{R}^{2}=.31$ and .92 , respectively (see table 5 ).

My original article compared this model's predictive performance during 1953-1961 with a simple "money multiplier" model where both the level and changes in the money supply were expressed as a function of only variable $X$ and three seasonal dummies. The relevant $\bar{R}^{2}$ 's for both money and commercial bank lending as predicted from this simpler model are given in table 6. All four equations explaining $M, \triangle M$, $L$ and $\triangle L$ are highly unstable between the first and second periods (see $F$-ratios in table 6 ).

The test of the original model's predictive performance in the second period as compared with the simple "money multiplier" model is not conclusive. The more complex model does better in a simulation experiment to predict the level of both money and commercial bank lending, but the simpler model produces substantially better predictions of changes in money and bank lending.

\section{Conclusion}

In my original article I wrote that "every
Table 6. $-\bar{R}^{2}$ for a Simple Multiplier Model

\begin{tabular}{cccccc}
\hline \hline Variable & $\begin{array}{c}1953-1961 \\
\text { Original } \\
\text { Coeff. }\end{array}$ & \multicolumn{2}{c}{$1962-1967$} & Orig. \\
Coeff. & $\begin{array}{c}\text { New } \\
\text { Coeff. }\end{array}$ & $\begin{array}{c}1953-1962 \\
\text { New } \\
\text { Coeff. }\end{array}$ & $\begin{array}{c}\text { F-Ratio for } \\
\text { Coeff. } \\
\text { Stability }\end{array}$ \\
\hline$M^{s}$ & .95 & .78 & .75 & .87 & 12.5 \\
$\Delta M^{s}$ & .91 & .55 & .72 & .67 & 5.7 \\
$L_{t}$ & .50 & .63 & .39 & .70 & 4.5 \\
$\Delta L_{t}$ & .72 & .34 & .54 & .37 & 10.3 \\
\hline
\end{tabular}

author hopes that his model will have predictive usefulness beyond the period over which its parameters were calculated" [6, p. 420]. Clearly, the predictive performance as judged by the $F$-test for coefficient stability, the simulation experiment, and the comparison with a simple "money multiplier" model is very low when the model is used during the 1962-1967 period. As previously suggested, the basic reason is that the model and the data used to estimate the parameters are more generally typical of a stationary economy than a truly developing one, and the equations fitted to the period 19531961 are largely inappropriate during the rapid development in Pakistan since 1961.

\section{REFERENCES}

[1] Chow, G. C., "Tests of Equality Between Sets of Coefficients in Two Regressions," Econometrica, 28 (1960), 591-605.

[2] Griffin, K. B., "Financing Development Plans in Pakistan," Pakistan Development Review, V (Winter 1965), 601-630.

[3] Johnston, J., Econometric Methods (New York: McGraw-Hill, 1963).

[4] Jorgenson, D. W., and M. I. Nadiri, "The Predictive Performance of Econometric Models of Quarterly Investment Behavior," Econometrica (forthcoming).

[5] Papanek, G. F., Pakistan's Development: Social Goals and Private Incentives (Cambridge: Harvard University Press, 1967).

[6] Snyder, W. W., "Money in a Developing Economy: A Case Study of Pakistan, 1953-61," this REVIEW, XLVI (Nov. 1964), 413-420.

[7] State Bank of Pakistan, Statistics on Scheduled Banks in Pakistan (Dec. 1961).

[8] State Bank of Pakistan, Statistics on Scheduled Banks in Pakistan (Dec. 1967).

[9] Theil, H., Economic Forecasts and Policy (Amsterdam: North Holland, 1958). 


